\title{
Penerapan knowledge sharing dengan media Portal BINUS di Bina Nusantara University
}

\author{
Syifa Naufal Qisty a* \\ aPusat Data dan Dokumentasi Ilmiah Lembaga Ilmu Pengetahuan Indonesia
}

\begin{abstract}
Abstrak
Dengan berkembangnya teknologi informasi, kini pengelolaan dokumen dilakukan secara digital dan paperless. Pengelolaan dokumen juga dilakukan sebagai salah satu implementasi kegiatan knowledge sharing pada suatu organisasi. Pengelolaan dokumen sebagai salah satu bagian dari kegiatan knowledge sharing salah satunya dilakukan oleh Bina Nusantara University (Binus). Artikel ini disusun untuk mengetahui bagaimana pengelolaan dokumen sebagai implementasi knowledge sharing di lingkungan Binus University. Metode yang digunakan yaitu metode deskriptif dengan melakukan wawancara dan kajian pustaka. Dari penelitian yang dilakukan, Binus University mengembangkan portal Binus sebagai wadah bagi karyawan untuk melakukan kegiatan knowledge sharing sekaligus mengelola dokumen yang ada di organisasi. Dokumen yang dikelola di antaranya dokumen lembaga seperti dokumen struktur organisasi, proses bisnis, tugas dan fungsi tiap direktorat, materi training, referensi dalam melakukan penugasan, sharing expertise, case study, case based reasoning, juga dokumen berupa ide, inovasi, dan pendapat yang ditulis dalam bentuk populer oleh karyawan di Binus.
\end{abstract}

Kata kunci: Pengelolaan dokumen; Manajemen pengetahuan; Berbagi pengetahuan

\section{The implementation of knowledge sharing with media Portal BINUS in Bina Nusantara University}

\begin{abstract}
With the development of information technology, document management is now done digitally and paperless. Document management is also carried out as an implementation of knowledge sharing activities in an organization. Document management as a part of knowledge sharing activities is one of which is carried out by Bina Nusantara University (Binus). This article is compiled to find out how document management is an implementation of knowledge sharing in the Binus University environment. The method used is descriptive method of conducting interviews and literature review. From the research conducted, Binus University developed the Binus portal as a forum for employees to carry out knowledge sharing activities as well as manage documents in the organization. The managed documents include institutional documents such as organizational structure documents, business processes, duties and functions of each directorate, training materials, references in carrying out assignments, sharing expertise, case studies, casebased reasoning, as well as documents in the form of ideas, innovations, and opinions written in popular form by employees at Binus.
\end{abstract}

Keywords: Document management; Knowledge management; Knowledge sharing

Korespondensi: Syifa Naufal Qisty, Pusat Data dan Dokumentasi Ilmiah, LIPI, Jl. Jend. Gatot Subroto 10, Jakarta 12710, Indonesia

Email: syifa20018@mail.unpad.ac.id

http://jurnal.unpad.ac.id/informatio

DOI: https://doi.org/10.24198/inf.v1i2.34055

Received: Juni 2021; Accepted: Juli 2020; Published: Juli 2021

(C) Informatio 2021. This is an open access article under the CC BY-SA license 


\section{PENDAHULUAN}

Pengelolaan dokumen bagi sebuah institusi merupakan kegiatan yang sangat penting mengingat dengan melakukan kegiatan pengelolaan dokumen akan memudahkan ketika melakukan pencarian kembali dokumen tersebut. Ketersediaan dokumen secara utuh, autentik, dan terpercaya akan memberikan dukungan nyata bagi kelangsungan suatu institusi. Dalam pengambilan keputusan, biasanya pimpinan akan mempertimbangkan informasi yang berada dalam sebuah dokumen. Sebaliknya, pengelolaan dokumen yang kurang baik dapat memberikan kinerja buruk terhadap suatu instansi.

Salah satu pengaruh dari perkembangan teknologi terhadap bidang dokumentasi adalah perubahan bentuk dokumen. Kini, dokumen memiliki dua bentuk umum, yaitu dokumen yang berbentuk hardcopy dan softcopy. Dokumen hardcopy merupakan salinan dokumen yang berbentuk cetak, biasanya berbentuk kertas dan dapat dibaca dan dilihat tanpa memerlukan alat bantu. Dokumen softcopy merupakan salinan dokumen berbentuk elektronik dan biasanya memerlukan alat bantu untuk melihatnya, seperti penyimpanan data pada file di flashdisk yang membutuhkan komputer untuk melihatnya.

Dengan berkembangnya teknologi, kini pengelolaan dokumen banyak dilakukan secara digital dan paperless. Dokumen akan terus bertambah seiring berjalannya waktu dengan kegiatan yang semakin kompleks dan fungsi institusi yang semakin berkembang. Oleh karena itu, pengelolaan dokumen secara digital dapat membangun manajemen organisasi yang efektif, efisien, dan produktif. Jika dokumen hanya disimpan dalam bentuk hardcopy, akan semakin bertumpuk dan membutuhkan ruangan untuk menyimpan dokumen tersebut. Di samping itu, proses pencarian dokumen akan membutuhkan banyak waktu.

Novianti dalam artikelnya yang berjudul "Perancangan Sistem Informasi Pengelolaan Dokumen (Studi kasus: Fakultas Ilmu Komputer Universitas Sriwijaya)", menyebutkan beberapa fungsi dokumen, yaitu: (1) Dokumen berfungsi sebagai alat komunikasi; (2) Dokumen memuat informasi penting untuk melaksanakan pekerjaan, contohnya dokumen perencanaan, dokumen persediaan barang dan lain-lain; (3) Dokumen berfungsi sebagai alat bukti; dan (4) Dokumen berfungsi sebagai "knowledge sharing" (Novianti \& Bardadi, 2017).

Pengetahuan merupakan suatu keahlian, keterampilan, pengalaman, dan pemahaman yang dimiliki seseorang. Pengetahuan bersifat subjektif, dinamis, dan kompleks. Pengetahuan juga diperoleh dari individu atau kelompok orang yang ada dalam suatu sistem organisasi. Dalam menjaga eksistensi organisasi, diperlukan pengelolaan pengetahuan/knowledge management. Knowledge management merupakan kegiatan mengumpulkan, menyusun, mengolah, menyimpan, dan mendistribusikan pengetahuan. Salah satu kegiatan yang terdapat dalam knowledge management adalah knowledge sharing. Knowledge sharing merupakan bagian dari knowledge management yang digunakan untuk memberikan kesempatan kepada anggota dari suatu institusi untuk 
berbagi pengetahuan yang dimilikinya. Kegiatan knowledge sharing dapat dilakukan jika setiap anggota memiliki kesempatan yang luas untuk menyampaikan ide dan pendapatnya. Peran berbagi pengetahuan di kalangan karyawan menjadi amat penting untuk meningkatkan kemampuan karyawan agar mampu berpikir secara logika yang diharapkan akan menghasilkan suatu bentuk inovasi. Jadi inovasi merupakan suatu proses dari ide melalui penelitian dan pengembangan akan menghasilkan prototype yang bisa dikomersilkan (Setiarso, 2006).

Nonaka dan Takeuchi (1995 dalam Junyati, 2019) menyebutkan bahwa penciptaan pengetahuan adalah proses sosial, di mana pengetahuan dalam organisasi sebagian besar tercipta dalam proses interaksi manusia. Proses ini dituangkan ke dalam sebuah model yang disebut model SECI (Socialization, Externalization, Combination, and Internalization). Tahap socialization merupakan tahap yang paling mendasar. Pada tahap ini terjadi proses berbagi pengetahuan melalui pengalaman langsung. Kegiatan diskusi, bercerita, berbagi pengalaman merupakan bentuk dari proses ini. Selanjutnya, tahap externalization, di mana pada tahap ini terjadi perubahan pengetahuan dari pengetahuan tacit menjadi pengetahuan explicit. Pada proses externalization, pengetahuan tacit yang ada dalam diri individu dituangkan ke dalam media lain sehingga mudah dimengerti dan dipelajari orang lain. Hasil dari proses eksternalisasi ini dapat berbentuk gambar, video, teks, dan sebagainya. Pengetahuan yang sudah dieksternalisasi kemudian dapat dikembangkan dan disebarluaskan melalui berbagai media yang lebih sistematis. Media yang sering digunakan biasanya berupa dokumen yang disampaikan pada proses pelatihan/pendidikan. Pengetahuan dapat digabungkan dengan pengetahuan lain yang telah ada yang pada akhirnya menghasilkan pengetahuan baru. Perubahan pengetahuan dari eksplicit menjadi pengetahuan tacit disebut juga dengan proses internalization. Perubahan ini terjadi ketika individu mencoba memahami suatu pengetahuan yang sudah ada atau melakukan penelitian terhadap suatu objek. Proses ini kemudian akan melahirkan pengetahuan baru pada diri individu tersebut.

Kegiatan knowledge sharing kini banyak dilakukan di berbagai institusi, salah satunya di Bina Nusantara University (Binus). Salah satu media yang digunakan oleh Binus untuk melakukan kegiatan transfer pengetahuan adalah dengan membangun sebuah portal pengelolaan dokumen yang diberi nama Portal Binus. Binus merupakan salah satu perguruan tinggi swasta yang memiliki direktorat khusus yang mengelola pengetahuan yang dimiliki karyawannya, yaitu Direktorat Knowledge Management and Innovation Binus. Penelitian ini dilakukan untuk mengetahui bagaimana penerapan knowledge sharing dengan media Portal Binus di Bina Nusantara University.

\section{METODE PENELITIAN}

Penelitian ini dilakukan dengan menggunakan pendekatan kualitatif. Pendekatan kualitatif digunakan untuk menjabarkan kejadian sosial secara deskriptif 
dan spesifik, agar pembaca memahami hal-hal yang terjadi di luar kejadian yang bersifat umum (Denzin \& Lincoln, 2018). Sebagaimana diungkapkan oleh Nasution (dalam Kurnia Firmansyah \& Dyah Putrisari, 2017), pendekatan kualitatif merupakan sebuah kegiatan pengamatan dalam lingkungan hidup, berinteraksi dengan mereka, kemudian berusaha memakai bahasa dan tafsiran mereka tentang dunia sekitarnya, dengan menggunakan metode ini, akan menghasilkan data-data deskriptif berupa kata-kata tertulis atau lisan dari orang-orang dan perilaku yang diamati.

Metode yang digunakan adalah deskriptif kualitatif. Penelitian deskriptif seperti disebutkan oleh Nana Sudjana dan Ibrahim (dalam Margareta, 2013), penelitian deskriptif merupakan penelitian yang berusaha mendeskripsikan suatu peristiwa dan kejadian yang terjadi pada saat sekarang, di mana peneliti berusaha memotret peristiwa dan kejadian yang menjadi pusat perhatian untuk kemudian digambarkan sebagaimana adanya. Penelitian deskriptif ini bertujuan untuk menggambarkan secara tepat bagaimana sifat-sifat suatu gejala sosial, baik individu maupun kelompok dan keadaan sosial tertentu.

Teknik pengumpulan data yang dilakukan adalah dengan melakukan wawancara kepada salah satu karyawan di BINUS dan studi pustaka. Hal ini dilakukan untuk mendapatkan data dari berbagai literatur seperti artikel ilmiah, makalah, buku, dan surat kabar.

\section{HASIL DAN PEMBAHASAN}

Manajemen pengetahuan adalah serangkaian kegiatan mengoordinasi pengetahuan dalam sebuah organisasi untuk mencapai tujuannya. Lebih dalam, Lumbantobing dalam (Prabowo, 2020) menyebutkan bahwa manajemen pengetahuan adalah suatu aktivitas sistematis yang dilakukan sebuah organisasi untuk berkreasi dan berbagi pengetahuan sehingga pengetahuan tersebut bisa dimanfaatkan untuk mencapai tujuan dari organisasi tersebut.

Definisi lain menurut Nonaka dan Konno yaitu knowledge management sebagai sesuatu yang vital secara eksplisit dan sistematis, serta proses yang berasosiasi pada pembentukan, pengorganisasian, difusi, penggunaan dan eksploitasi (Maryani, 2012). Definisi tersebut merupakan definisi rumusan Skyrme yang paling merepresentasikan pengertian knowledge management berdasarkan pengalaman dan kepakarannya. Definisi yang lain menyebutkan, "KM is the process through which organizations generate value from intellectual and knowledge based assets," yang diterjemahkan sebagai knowledge management adalah proses bagaimana sebuah organisasi mengambil keuntungan dari aset berbasis intelektual dan pengetahuan.

Pengetahuan dapat berpindah dari satu tempat ke tempat lain, dari satu orang ke orang lain. Menurut Lertpittayapoom, ada 3 jenis pengetahuan, yaitu tacit, eksplisit, dan implisit. Namun, banyak juga para ahli yang mengkategorikannya dengan nama yang 
berbeda namun memiliki makna yang sama dalam konsep. Tacit knowledge merupakan pengetahuan yang masih tersembunyi dalam bentuk ide, keahlian seseorang, pengalaman, pendapat seseorang dalam diskusi, dan sejenisnya, selama pengetahuan itu belum terdokumentasikan. Pengetahuan yang sudah terdokumentasikan, terekam dalam berbagai bentuk seperti buku, majalah, dokumen, dan media lainnya disebut explicit knowledge. Implicit knowledge merupakan pengetahuan yang masih samar antara explicit dan tacit namun cenderung nyata dan lebih mengarah ke explicit knowledge.

Dalam manajemen pengetahuan (knowledge management), knowledge sharing merupakan salah satu bagian dari proses-proses manajemen pengetahuan. Menurut Tobing (2007: 9) knowledge sharing adalah tahapan diseminasi (penyebaran) dan penyediaan pengetahuan pada saat yang tepat untuk karyawan yang membutuhkan. Gerard dalam Prabowo (2020) menyatakan bahwa pengetahuan yang sifatnya eksplicit (dapat dilihat) hanya $20 \%$, sementara yang sifatnya tacit mencapai $80 \%$. Hal ini menunjukkan bahwa jika pengetahuan bisa dimanfaatkan dengan optimal maka pengetahuan tersebut akan sangat membantu manusia dalam bekerja. Dalam bukunya, Yusup (2012) menjelaskan beberapa karakteristik pengetahuan tacit, di antaranya:

Pengetahuan setiap orang itu unik, independen, dan tidak semuanya dapat diungkapkan atau dikodifikasikan menjadi pengetahuan eksplisit.

Meskipun jenis pengetahuan tacit itu tersembunyi di balik keunikan personal seseorang, pengetahuan tacit erat kaitannya dengan tindakan orang tersebut dalam mencapai dan mengekspresikan nilai-nilainya.

Pengetahuan tacit akan muncul sedikit sekali/sama sekali tanpa bantuan pihak lain. Ide dan kreativitasnya muncul melalui kemampuan praktis seseorang.

- $\quad$ Pengetahuan tacit akan muncul dalam forum-forum komunikasi kelompok, yang biasanya terjadi secara spontan dan bukan akibat dukungan orang lain.

Becerra-Fernandez dalam Siagian dan Dana (2009: 40) menjelaskan bahwa knowledge sharing adalah sebuah proses di mana pengetahuan eksplisit atau tacit dikomunikasikan kepada individu lainnya. Menurutnya pula, ada tiga penjelasan mengenai knowledge sharing, yakni:

1. Knowledge sharing berarti transfer/ pemindahan yang efektif, sehingga penerima pengetahuan tersebut dapat memahaminya untuk dapat melakukannya dengan cara yang benar;

2. Dalam knowledge sharing, yang dibagikan adalah pengetahuan itu sendiri dari pada rekomendasi-rekomendasi berdasarkan pengetahuan tersebut;

3. Knowledge sharing dapat dilakukan antarindividu demikian juga antarkelompok, antardepartemen atau antarorganisasi. Definisi lain menurut Tiwana menjelaskan 
bahwa dalam manajemen pengetahuan, diharapkan jika seorang karyawan mempelajari sesuatu maka karyawan lainnya di dalam organisasi/perusahaan tersebut juga mengetahui atau mengerti apa yang dipelajari oleh karyawan tersebut (Siagian \& Sensuse, 2009). Oleh karena itu, diperlukan knowledge sharing yang efektif supaya manajemen pengetahuan berhasil dijalankan dalam suatu organisasi/perusahaan.

Chen, Irene Y.L, Nian-Shing Chen, dan Kinshuk pada tahun 2009 menggambarkan beberapa aspek yang dapat mempengaruhi perilaku knowledge sharing, yaitu:

(1) Norma dan nilai yang dianut oleh seseorang. Informasi dan jenis pengetahuan apa saja yang akan dibagikan kepada orang lain bergantung dari nilai yang dianut oleh seseorang. Seseorang dapat memilih untuk membagikan pengetahuan atau pengalaman unik yang hanya dimilikinya kepada orang lain atau tidak.

(2) Sikap seseorang. Seseorang yang memiliki pengetahuan tertentu tidak serta merta membagi pengetahuannya kepada seluruh anggota organisasi. Memilih seseorang untuk diajak saling berbagi merupakan sifat selektif seseorang dalam melakukan knowledge sharing.

(3) Perceived behavioral control. Proses penerimaan dan pengetahuan dari kegiatan knowledge sharing dikelola dengan cara, sikap, dan perilaku yang berbeda oleh setiap orang.

(4) Social network ties. Hubungan sosial seseorang memengaruhi perilaku seseorang ketika melakukan knowledge sharing, baik jaringan sosial yang bersifat konvensional maupun yang menggunakan teknologi komunikasi dan informasi. Namun, dengan adanya teknologi komunikasi, kesempatan seseorang untuk berbagi informasi dan pengetahuan menjadi sangat luas (Yusup, 2012).

Manajemen pengetahuan adalah sebuah proses sirkulasi antara penciptaan pengetahuan, integrasi, dan diseminasi (Fischer \& Ostwald, 2001). Creation secara bahasa diartikan sebagai penciptaan. Dalam konteks sirkulasi pengetahuan di atas, yang dimaksud penciptaan adalah adanya kemauan dari SDM untuk mengeluarkan pengetahuan yang masih bersifat tacit agar bisa digunakan untuk kepentingan organisasi. Setelah pengetahuan muncul dari masing-masing individu maka perlu adanya integrasi antarpengetahuan tersebut untuk menyamakan persepsi agar tidak terjadi kesalahpahaman. Output dari terintegrasinya pengetahuan antaranggota organisasi akan menghasilkan pemecahan masalah yang menguntungkan semua (Prabowo, 2020).

Perjalanan Yayasan Bina Nusantara (BINUS) dimulai pada tanggal 21 Oktober 1974. Berawal dari kursus jangka pendek bernama Kursus Komputer Modern, yang kemudian berkembang karena landasan yang kuat dan visi yang komprehensif. Karena tuntutan yang tinggi dan perkembangannya yang pesat, pada 1 Juli 1981 Kursus Komputer Modern telah berkembang menjadi “Akademi Teknik Komputer (ATK)” dengan Manajemen Informatika 
sebagai jurusan pertama. ATK tersebut terdaftar pada 13 Juli 1984 dan setahun kemudian tepatnya pada tanggal 1 Juli 1985 berubah menjadi AMIK Jakarta. Pada 21 September 1985, AMIK Jakarta berubah nama menjadi AMIK Bina Nusantara.

AMIK Bina Nusantara mencatatkan prestasi yang luar biasa di usianya yang relatif muda ketika terpilih sebagai akademi komputer terbaik oleh Kementerian Pendidikan dan Kebudayaan melalui Dikti Kabupaten III pada 17 Maret 1986. Perlunya tenaga profesional di bidang teknologi informasi, AMIK semakin berkembang, dan pada 1 Juli 1986 resmi terdaftar sebagai Sekolah Tinggi Manajemen Informatika dan Komputer (STMIK). Pada 9 November 1987, terjadi penggabungan antara AMIK Bina Nusantara dan STMIK Bina Nusantara. Institusi tersebut menyelenggarakan program diploma 3 (D3) dan sarjana (S1). Status akreditasi "Disamakan" untuk semua jurusan dan jenjang diperoleh pada 18 Maret 1992. Pada tahun berikutnya, STMIK Bina Nusantara membuka Program Magister Manajemen Sistem Informasi pertama di Indonesia. Program tersebut resmi terdaftar pada 10 Mei 1993.

Setelah melalui ketekunan dan kerja keras selama bertahun-tahun, Universitas Bina Nusantara (Universitas Bina Nusantara atau UBINUS) resmi terdaftar dan berdiri pada 8 Agustus 1996. STMIK Bina Nusantara kemudian dilebur menjadi Universitas Bina Nusantara pada 20 Desember 1998. Saat itu UBINUS memiliki Fakultas Ilmu Komputer (Fakultas Ilmu Komputer), Fakultas Ekonomi, Fakultas Teknik (Fakultas Teknik), Fakultas Sastra (Fakultas Sastra), Fakultas Matematika dan Ilmu Pengetahuan Alam (Fakultas MIPA) dan Magister (S2) Program Manajemen Sistem Informasi. Pada tahun yang sama Binus mendirikan Sekolah Menengah Atas yang berlokasi di Kemanggisan (pada tahun 2003 lokasi sekolah pindah ke Simprug). Namun UBINUS tidak berhenti sampai di situ. UBINUS terus memperluas jangkauan mereka di bidang pendidikan. Pada 20 April 2007, Universitas Bina Nusantara menambah Fakultas Psikologi serta Fakultas Komunikasi \& Multimedia. Sejak saat itu Binus terus berkembang, dan saat ini memiliki dua jenis institusi pendidikan: Binus Higher Education yang memiliki 11 kampus di enam kota yang menyediakan pendidikan tinggi mulai dari D3 sampai dengan S3 dan BINUS School Education, berada di tiga kota yang menyediakan pendidikan mulai dari TK hingga SMA.

Dengan semakin berkembangnya Binus, jumlah pegawainya pun semakin bertambah hinga mencapai lebih dari 5000 karyawan. Dengan jumlah karyawan sebanyak itu diperlukan sebuah wadah atau tempat untuk para karyawannya berbagi pengetahuan yang dimiliki agar bisa dibagikan kepada karyawan lainnya sehingga selain pengetahuan tersebut terdokumentasi dengan baik, karyawan juga bisa menambah pengetahuannya. Dengan adanya semangat berbagi pengetahuan tersebut diharapkan bisa membantu mengembangkan organisasi menjadi lebih besar lagi. Oleh karena itu dibuatlah sebuah portal bernama http://portal.binus.edu/ yang menjadi tempat karyawan Binus untuk berbagi pengetahuannya. Portal tersebut dibuat oleh Direktorat Knowledge Management 
and Innovation Binus. Seluruh karyawan Binus bisa mengakses http://portal.binus.edu/ dengan login terlebih dahulu menggunakan email Binus dan password-nya. Untuk file tertentu jika ingin mengaksesnya harus memasukkan kembali email Binus dan password. Namun tidak semua file bisa diakses oleh seluruh karyawan. Ada file tertentu yang hanya bisa diakses oleh karyawan dengan jabatan tertentu.

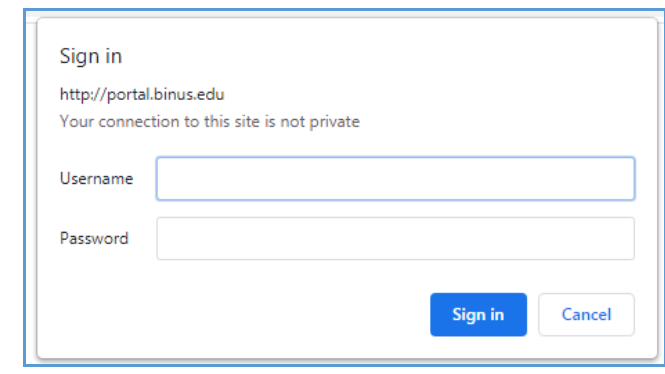

Gambar 1. Tampilan login page http://portal.binus.edu/

Sumber: Dokumentasi Peneliti (2021)

Portal http://portal.binus.edu/ memiliki 8 menu utama yaitu Binuspedia, Resource, Achievement, Research, Reference, Whistleblowing, KM Pointe Incentive System dan Binus Page.

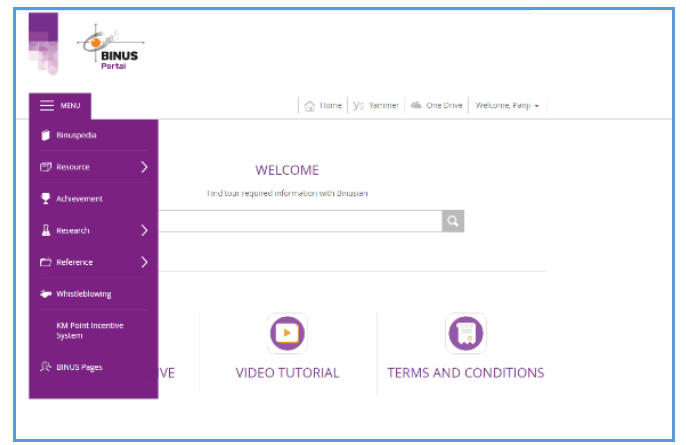

Gambar 2. Tampilan halaman utama http://portal.binus.edu/ Sumber: Dokumentasi Peneliti (2021)

Menu Binuspedia berisi artikel atau tulisan karyawan Binus yang bersifat populer (nonilmiah). Selain artikel atau tulisan karyawan Binus, pada menu Binuspedia karyawan juga bisa berbagi informasi dari sumber-sumber lain dengan mencantumkan sumber aslinya. Pada setiap artikel di Binuspedia disediakan menu untuk membagikan tulisan tersebut. Setiap karyawan bisa memberikan nilai pada artikel yang ada di Binuspedia. Sistem penilaian menggunakan bintang 1 sampai bintang 5 .

Menu Resources berisi informasi yang terkait dengan segala hal yang berkaitan dengan Binus. Pada menu ini, unit atau karyawan bisa mengunggah informasi apapun terkait pekerjaan. Menu Resources memiliki beberapa submenu yaitu:

1. Quality Standards 
2. Job Description

3. Organization Structure

4. Documents

5. Photo

6. Video

7. Library Update

8. Business Card

9. BINUS on YouTube

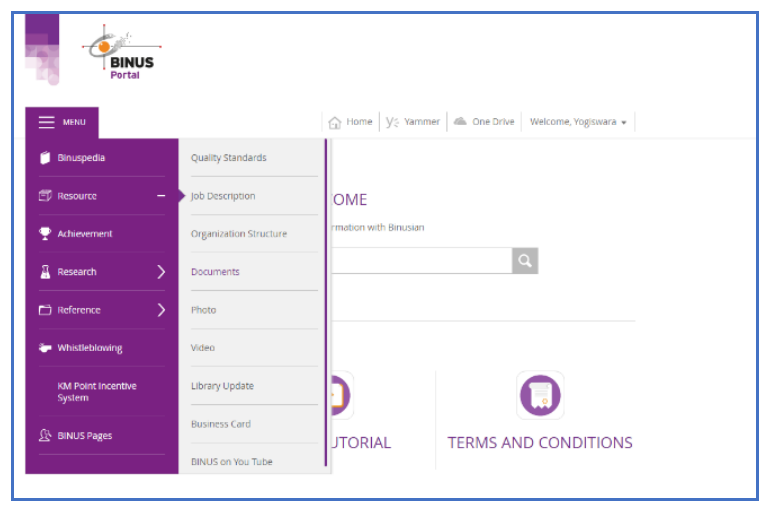

Gambar 3. Tampilan Menu Resource dan sub menunya Sumber: Dokumentasi Peneliti (2021)

Submenu Quality Standards yang memuat informasi mengenai prosedur dan instruksi kerja yang ada di setiap unit yang ada di Binus. File prosedur dan instruksi kerja tersebut tersedia dalam format Word yang dapat diunduh. Karyawan yang mengunduh hanya perlu memasukkan email Binus dan password-nya untuk membuka file tersebut. Prosedur dan instruksi kerja yang ada di Binus dibuat berdasarkan ISO 9001:2015. Prosedur dan instruksi kerja dievaluasi setiap 2 tahun sekali atau kapanpun jika terdapat perubahan di lapangan. Submenu Job Description berisi informasi mengenai deskripsi pekerjaan jabatan atau posisi yang ada di Binus. File job description tersebut tersedia dalam format PDF. Sama halnya dengan prosedur dan instruksi kerja, untuk mengaksesnya harus menggunakan email Binus dan password-nya. Submenu selanjutnya adalah Organization Structure. Pada menu ini karyawan bisa melihat struktur organisasi yang ada di seluruh unit yang ada di Binus. Cara mengaksesnya sama dengan dua submenu sebelumnya. Pada submenu documents terdapat folder-folder yang disusun secara alfabetis berdasarkan nama-nama unit yang ada di Binus.

Setiap unit bisa menggunggah informasi apapun terkait pekerjaan di folder unit masing-masing, misalnya catatan meeting, dokumentasi kegiatan unit, dan dokumen lainnya. Pada submenu foto dan video berisi foto dan video kegiatan unit-unit yang ada di Binus. Submenu Library Update merupakan submenu yang diperuntukan khusus untuk Library BINUS menggunggah artikel-artikel yang berhubungan dengan dunia pendidikan 
yang didapat dari majalah serta surat kabar yang dilanggan oleh Library BINUS. Submenu selanjutnya yang ada di menu Resources adalah submenu Business Card. Pada menu ini karyawan bisa menggunggah informasi mengenai orang-orang di luar BINUS yang ditemui terkait pekerjaan. Informasi yang diunggah adalah nama, pekerjaan, alamat kantor, email, dan nomor ponsel. Dengan adanya menu ini, mempermudah karyawan untuk mencari informasi mengenai orang-orang yang pernah berinteraksi dengan BINUS. Submenu terakhir adalah BINUS on Youtube. Pada menu ini karyawan bisa mengakses video-video yang diunggah oleh unit-unit yang ada di BINUS di akun YouTube unit tersebut. Misalnya video-video hasil liputan BINUS TV atau video-video tutorial cara mengakses e-book yang diunggah oleh Library BINUS.

Menu Achievements berisi informasi mengenai pencapaian dan prestasi yang diraih oleh Binus, baik prestasi individu siswa, mahasiswa, pengajar, karyawan saat mewakili Binus, maupun prestasi yang diraih oleh unit, jurusan, universitas ataupun Yayasan Binus secara keseluruhan. Menu Research berisi artikel ilmiah yang ditulis oleh dosen-dosen Binus University yang diterbitkan di jurnal Binus. Pada menu research ini juga terdapat template proposal penelitian dan panduan cara-cara penulisan artikel ilmiah. Menu Reference berisi sumber-sumber referensi yang bisa dijadikan bahan karyawan Binus untuk pengembangan diri atau pengembangan unit tempat karyawan tersebut bekerja. Pada menu ini terdapat 8 submenu yaitu:

1. Training document

2. Material

3. Best Practices

4. Sharing Expertise

5. Case Base Reasoning

6. Book Review

7. Benchmarking

8. Case Study

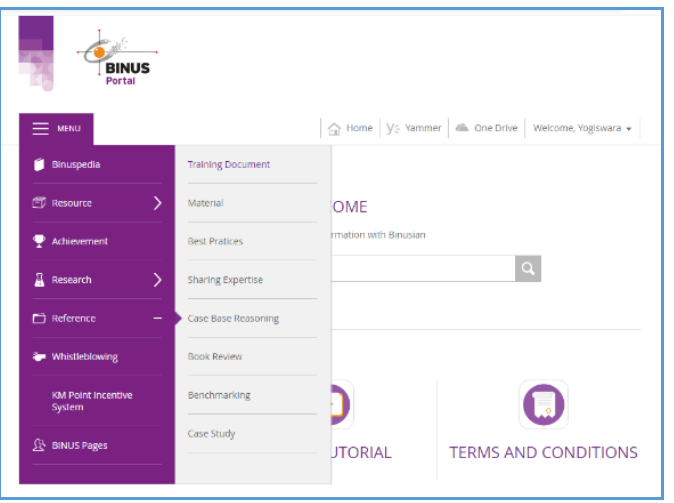

Gambar 4. Tampilan menu Reference dan submenunya

Sumber: Dokumentasi Peneliti (2021) 
Submenu Training Document berisi materi training yang telah diselenggarakan Binus atau pernah diikuti oleh karyawan Binus di luar. Dengan adanya menu ini karyawan yang tidak sempat mengikuti training bisa membaca materi training yang telah terlewat. Submenu Material berisi materi bacaan terkait pengembangan diri, bisa berupa artikel, $e^{-}$ book, paper, dan lain-lain. Submenu Best Practices yang berisi teknik, metode, proses atau inovasi terbaik yang telah dijalankan oleh unit-unit yang ada di Binus dalam menjalankan suatu pekerjaan tertentu dengan cara yang lebih efektif dan efisien dengan hasil yang maksimal. Dengan adanya menu ini seluruh karyawan Binus bisa mempelajari best practices yang ada di unit lain dan jika ada yang cocok bisa menerapkan di unitnya sendiri.

Submenu Sharing Expertise yang berisi materi yang dibuat oleh karyawan Binus sesuai dengan keahlian yang dimiliki untuk berbagi dengan karyawan lainnya. Misalnya, tips fotografi dari karyawan yang mahir dalam bidang fotografi. Dengan adanya menu ini karyawan bisa belajar keahlian lain untuk menambah soft skill yang dimiliki. Selain itu, untuk karyawan yang membagikan keahliannya bisa semakin memperkuat pengetahuan yang dimiliki karena telah menulis dan membagikannya. Menu Case Based Reasoning yang berisi tentang masalah-masalah baru yang dihadapi oleh karyawan atau unit yang ada di Binus yang belum pernah terjadi sebelumnya serta cara untuk mengatasi masalah tersebut. Terkadang masalah yang muncul tersebut di luar dari prosedur yang sudah ada sehingga dengan adanya masalah tersebut dapat menjadi dasar perubahan atau revisi terhadap prosedur atau instruksi kerja yang sudah.

Submenu Book Review berisi ulasan buku yang pernah dibaca oleh karyawan Binus. Dengan adanya menu ini karyawan bisa berbagi informasi tentang buku yang disukai dan mendapatkan tanggapan dari karyawan lainnya. Submenu Benchmarking berisi materi hasil studi banding karyawan atau unit yang ada di Binus dengan institusi lain di luar Binus. Hasil benchmarking atau studi banding kerap dijadikan acuan unit yang ada di Binus untuk menciptakan inovasi serupa atau bahkan lebih baik untuk diterapkan di BINUS. Submenu Case Study memuat case study yang dibuat oleh para pengajar di Binus dan diterbitkan oleh Binus Case Study Center. Saat ini case study yang ada mencakup beberapa topik berikut ini: akuntansi keuangan, ekonomi dan kebijakan publik, wirausaha dan inovasi, kepemimpinan dan budaya organisasi, pemasaran, manajemen strategi, dan Manajemen teknologi operasi. Menu Whistleblowing diperuntukkan untuk karyawan yang ingin melaporkan mengenai konten di Portal Binus pada http://portal.binus.edu/ yang dirasa tidak sesuai, misalnya terdapat indikasi plagiarisme, link tidak dapat diakses, dan lain-lain. Kemudian administrator akan melakukan verifikasi dan pengecekan terhadap laporan tersebut dan segera menindaklanjuti laporan.

Pada menu KM Point Incentive System karyawan bisa melihat berapa poin yang telah dia capai di http://portal.binus.edu/. Setiap karyawan yang berkontribusi mengunggah materi ke http://portal.binus.edu/ akan mendapat poin sesuai dengan jenis 
materi yang diunggah. KM Point Incentive System dibagi menjadi dua kategori: individual dan jurusan/prodi atau center. Karyawan bisa menukarkan poin yang dikumpulkan dengan voucher belanja 100 poin bisa ditukar dengan Rp.50.000,- voucher belanja. Tujuan dibuatnya KM Point Incentive System adalah memberikan apresiasi kepada karyawan yang berbagi pengetahuan, menumbuhkembangkan budaya berbagi pengetahuan di Binus, memperluas keterlibatan karyawan dalam berbagi pengetahuan, dan menumbuhkembangkan kepedulian terhadap kualitas konten. Pada menu BINUS Pages karyawan bisa melakukan pencarian karyawan lainnya di Binus. Pencarian bisa dilakukan berdasarkan nama atau unit tempat karyawan bekerja.

Pemanfaatan Portal Binus sebagai media dalam berbagi pengetahuan dapat mencakup proses pengetahuan model SECI Nonaka dan Takeuchi. Namun, proses sosialisasi tidak banyak terjadi melalui media ini. Hal ini dikarenakan proses sosialisasi biasanya dilakukan dengan tatap muka. Proses eksternalisasi melalui media Portal Binus difasilitasi dengan tersedianya beberapa menu dan submenu dalam Portal Binus, seperti dalam menu Research atau Reference yang memiliki submenu material, best practices, sharing expertise, case based reasoning, dan book review. Karyawan dapat mengalami proses eksternalisasi dengan menuliskan ide-ide, inovasi, dan pengetahuan yang dimilikinya melalui submenu yang ada di Portal Binus.

Proses kombinasi dapat terjadi ketika karyawan menggunakan dokumen-dokumen yang ada di dalam portal sehingga menciptakan informasi atau inovasi baru. Misalnya seperti yang ada pada submenu Benchmarking. Dengan melihat dokumen yang ada pada submenu ini, divisi yang ada di Binus dapat melihat hasil benchmarking di institusi lain untuk kemudian menciptakan inovasi baru. Portal Binus yang memiliki banyak dokumen juga dapat membuat proses internalisasi pada karyawan yang membaca dokumen yang ada di dalam portal.

Portal BINUS menjadi salah satu implementasi dari kegiatan knowledge sharing yang ada di Binus. Portal ini dapat mencakup komponen yang diperlukan dalam manajemen pengetahuan. Portal merupakan wujud dari teknologi internet yang dimanfaatkan oleh organisasi. Karyawan dapat dengan mudah mengungkapkan ide dan pendapat yang ada dalam pikirannya dengan menyampaikannya melalui menu yang ada dalam portal. Pimpinan organisasi juga dapat menerapkan teknik-teknik manajemennya melalui portal tersebut. Dokumen-dokumen terkait organisasi berupa standard operational procedure (SOP), tugas dan fungsi setiap direktorat, struktur organisasi, ukuran dan indikator pengendalian dapat dengan mudah diakses oleh karyawan melalui menu yang ada dalam portal. Demikan pula dengan ide-ide, inovasi, dan knowledge atau pengetahuan baru dapat disampaikan pula melalui Portal Binus. 


\section{SIMPULAN}

Bina Nusantara University melalui Direktorat Knowledge Management and Innovation mengembangkan Portal Binus yang digunakan sebagai wadah untuk berbagi pengetahuan dalam lingkup organisasinya. Portal ini sekaligus sebagai tempat pengelolaan dokumen yang ada di lingkungan Binus. Dokumen yang dikelola di antaranya dokumen lembaga seperti dokumen struktur organisasi, proses bisnis, tugas dan fungsi setiap direktorat, materi training, referensi dalam melakukan penugasan, sharing expertise, case study, case based reasoning, juga dokumen berupa ide, inovasi, dan pendapat yang ditulis dalam bentuk populer oleh karyawan di Binus.

\section{Kontribusi Pada Keilmuan}

Penelitian ini merupakan kajian dalam bidang Perpustakaan yang mengkaji knowledge management atau knowledge sharing. Penelitian ini juga berkaitan dengan ilmu dokumentasi. Hasil penelitian ini dapat menjadi dasar untuk penelitian selanjutnya atau penelitian bidang sejenis mengenai knowledge sharing dan dokumentasi. Penelitian ini juga dapat menjadi sumber inspirasi bagi penelitian lain di bidang knowledge management dan dokumentasi.

\section{Pernyataan Minat Kajian}

Peneliti bernama Syifa Naufal Qisty memiliki minat kajian di bidang perpustakaan, dokumentasi, research data management, dan research data services.

\section{Kontribusi Pihak Lain}

Peneliti mengucapkan terima kasih kepada Yogiswara Javmika selaku Head of Library and Knowledge Center BINUS University @Senayan Campus dan Kementrian Ristek/BRIN selaku pemberi dana.

\section{DAFTAR PUSTAKA}

Denzin, N. K., \& Lincoln, Y. S. (2018). The SAGE handbook of qualitative research. California: SAGE Publications.

Fischer, G., \& Ostwald, J. (2001). Knowledge management: problems, promises, realities, and challenges. IEEE Intelligent Systems, 16(1), 60-72. https://doi.org/10.1109/5254.912386

Junyati. (2019). SECI model. Retrieved from BINUS School of Information System. https://sis.binus.ac.id/2019/04/03/seci-model/

Kurnia, F. E., \& Dyah, P. N. (2017). Sistem religi dan kepercayaan masyarakat kampung. Jurnal Pengabdian Kepada Masyarakat, 1(4), 236-243. https://doi.org/10.24198/tornare.v3i1.29840

Margareta, S. (2013). Hubungan pelaksanaan sistem kearsipan dengan efektivitas pengambilan keputusan pimpinan: studi deskriptif analisis kuantitatif di Sub Bagian Kepegawaian dan Umum lingkungan kantor Dinas Pendidikan Provinsi Jawa Barat 
(Skripsi). Retrieved from Repository UPI. http://repository.upi.edu/1605/

Maryani, M. (2012). Implementasi knowledge management pada KLPM-PTS: pembentukan sharing culture antar anggota KLPM-PTS di Indonesia. ComTech: Computer, Mathematics and Engineering Applications, 3(1), 142-148. https://doi.org/10.21512/comtech.v3i1.2393

Novianti, H., \& Bardadi, A. (2017). Perancangan sistem informasi pengelolaan dokumen (studi kasus: Fakultas Ilmu Komputer Universitas Sriwijaya). Konferensi Nasional Teknologi Informasi dan Aplikasinya 4(55), 198-201. Retrieved from http://seminar.ilkom.unsri.ac.id/index.php/kntia/article/view/1215

Prabowo, T. T. (2020). Penerapan manajemen pengetahuan dalam pengelolaan dokumen di Perpustakaan STIKes Guna Bangsa. Khazanah: Jurnal Pengembangan Kearsipan, 13(1), 17-33. https://doi.org/10.22146/khazanah.53067

Setiarso, B. (2006). Berbagi pengetahuan: siapa yang mengelola pengetahuan?. Komunitas ELearning IlmuKomputer.Com. Retrieved from https://eprints.rclis.org

Siagian, B. T., \& Sensuse, D. I. (2009). Pemetaan dan analisis knowledge sharing pada Situs Forum Komunitas Online Kaskus. Jurnal Sistem Informasi MTI-UI, 6(1), 68-70. https://doi.org/10.21609/jsi.v6i1.277

Yusup, P. M. (2012). Perspektif manajemen pengetahuan informasi, komunikasi, pendidikan dan perpustakaan. Jakarta: Rajawali. 